\title{
PEMANFAATAN LIMBAH ORGANIK DENGAN PENAMBAHAN BIOFUND UNTUK MENINGKATKAN PRODUKSI TANAMAN JAGUNG (Zea mays L.)
}

\author{
Murdaningsih \\ Fakultas Pertanian Universitas Flores \\ ningsih_murda@yahoo.co.id
}

\section{ABSTRACT \\ The Use of Organic Waste By Additon Biofund To Increase The Production of Corn (Zea mays)}

Organic waste comes from pigswill livestock can used as plant nutrient source . Organic material have significant influence on agriculture productivity. Organic material added continuelly was an effective ways to mantain soil health, it will provide soil organisms food, increasing available nutrient and mantain soil physic characteristic. Otherwise, organic waste added still not get an optimal result. Thats why, organic waste added from pigswill livestock and biofund as activator was one of an alternative ways.

This study was aimed to know pigswill livestock waste potensize as organic material added on nutrient availability in order to improving plant productivity, and the influence on plant production. This study was consist on two stages; i.e. the first study was soil incubation for 20 days; and the second was maize plant aplication. The method used was Complete Factorial Randomized design with 2 factors and 3 replicates.

The results showed that pigswill livestock organic waste and biofund will increase soil C, N, P, and $\mathrm{K}$ exchange. It happened especially on FIB1 and F1B3 treatment ; it marks with increasing trend on every weeks. The highest production was found on F1B3 (256.63 gplant"') and the lowest on FIBO (I I7.U gplant').

Keywords: organic waste, biofund, plant productivity

\section{PENDAHULUAN}

Limbah organik yang berasal dari sisa makanan ternak dapat dimanfaatkan sebagai sumber unsur hara bagi tanaman. Bahan organik mempunyai dua fungsi utama, yakni secara langsung menyediakan unsur hara melalui proses dekomposisi, dan secara tidak langsung menambah kadar bahan organik tanah yang dapat memperbaiki sifat fisik tanah serta mengatur penyediaan unsur hara dikemudian hari (Handayanto et al, 1994)., karena salah satu kunci keberhasilan dalam pengelolaan sifat flsik tanah adalah bagaimana dapat mempertahankan kadar bahan organik. Kadar bahan organik tanah ini adalah merupakan hasil dekomposisi dari sisa bahan makanan ternak yangdiberikan.

Proses dekomposisi yang berasal dari sisa bahan tersebut dapat berlangsung sekitar 3 sampai 5 bulan, namun bahan-bahan tersebut jika diformulasikan dengan penambahan formula kultur mikroba "Bio Fund" maka waktu yang dibutuhkan hanya I sampai 2 bulan. Biofund adalah dekomposer yang sangat efektif untuk keperluan di bidang pertanian. Salah satu manfaatnya dari Bio Fund adalah mempercepat proses pembuatan kompos baik dari sampah atau kotoran ternak, sekaligus mengurangi efek bau menyengat sampai dengan $50 \%$ selamaprosesnya.

Kedua bahan tersebut, baik limbah pakan ternak maupun Bio Fund memiliki keunggulan yang cukup baik dalam bidang pertanian. Keunggulan tersebut antara lain sebagai penyedia unsur hara ramah lingkungan. Namun demikian pemanfaatannya belum dimanfaatkannya secara baik, padahal produksi limbah makin hari makin bertambah. Dengan demikian maka perlu diadakan penelitian pemanfaatan limbah organik sisa makanan ternak dan penggunaan biofund untuk mempercepat proses dekomposisi yang pada akhirnya dapat meningkatkan produksi tanaman.

Penelitian ini bertujuan untuk mempelajari potensi limbah makanan ternak sebagai masukan bahan organik untuk penyediaan unsur hara serta pengaruhnya terhadapproduksi tanamanjagung.

\section{METODE PENELITIAN}

Penelitian ini dilakukan dengan metode yang digunakan adalah Rancangan Acak Lengkap Faktoriai dengan 2 faktor dan diulang sebanyak 3 kali. Faktor pertama terdiri dari $\mathrm{FO}=$ kontrol, dan $\mathrm{Fl}=\mathrm{I}$ literbiofund $/ 200 \mathrm{~kg}$ bahan. Sedangkan Faktor kedua Sisa makanan ternak terdiri dari $\mathrm{BO}=$ kontrol, $\mathrm{Bl}=$ dicacah kasar, $\mathrm{F} 2$ 
= dicacah sedang, dan F3 = dicacah halus. Hasil penelitian ini dianalisis dengan menggunakan Anova dan dilanjutkan dengan uj i BNT.

\section{HASILDAN PEMBAHASAN}

\section{TinggiTanaman Jagung}

Hasil analisis ragam periakuan pemberian limbah makanan ternak menunjukan pengaruh nyata terhadap tinggi tanaman pada setiap periode pengamatan. Perbedaan tersebut terutama pada terlihat pada periakuan iimbah dengan cacahan hatus berbeda nyata dengan limbah yang dicacah kasar, sementara tanpa menggunakan limbah makanan ternak tidak menunjukan perbedaan yang nyata pada masing-masing pengamatan 30 dan 60 HST.

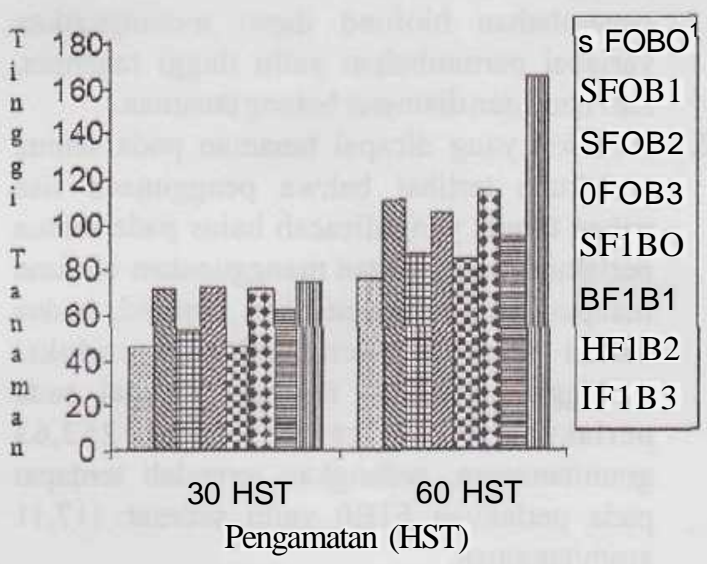

Gambar 1. Pengaruh limbah makanan ternak dan biofund terhadap tinggi Tanaman pada umur30dan60HST.

\section{DiameterBa(ang}

Hasil analisis ragam periakuan pemberian limbah makanan ternak dan biofund pada pengamatan diameter batang untuk periode pengamatan 30 HST menunjukan tidak berbeda nyata kecuali untuk périakuan F-IB3. Sedangkan untuk pengamatan' 60 HST menunjukkan perbedaan nyata antar periakuan. Pada periode pengamatan tersebut ( 30 dan $60 \mathrm{HST}$ ) terlihatjelas pada periode pengamatan 60 HST sebagaimana terlihat pada Gam bar 2.

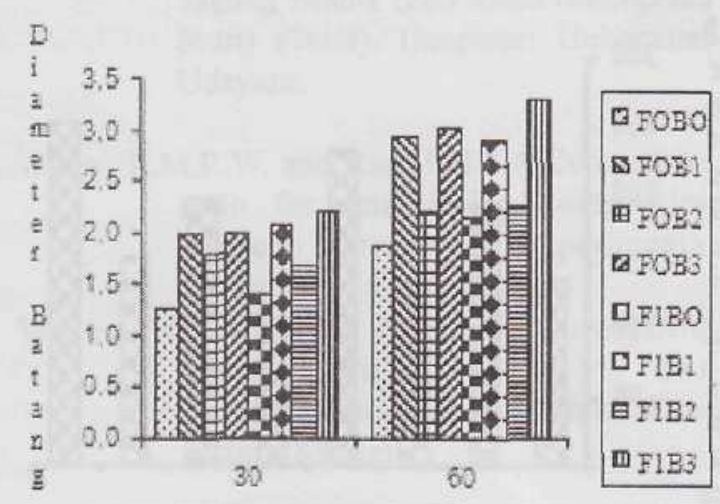

Pengamatan (HST)

Gambar2. Pengaruh limbah makanan ternak dan biofund terhadap Diameter Batang padaumur30dan60HST.

\section{LuasDaun}

Hasil analisis ragam periakuan pemberian limbah makanan ternak dan penambahan biofund menunjukan pengaruh yang nyata pada periode pengamatan 30 dan $60 \mathrm{HST}$. Perbedaan periakuan tersebut lebih jelasiiya dapat di 1 that pada Gam bar 3 . Dan gambar tersebut terlihat bahwa periakuan penggunaan sisa pakan yang dicacah kasar dan yang dicacah halus memberikan pengaruh pert urn buhan yang cukup signifikan jika dibandingkan dengan kontrol.

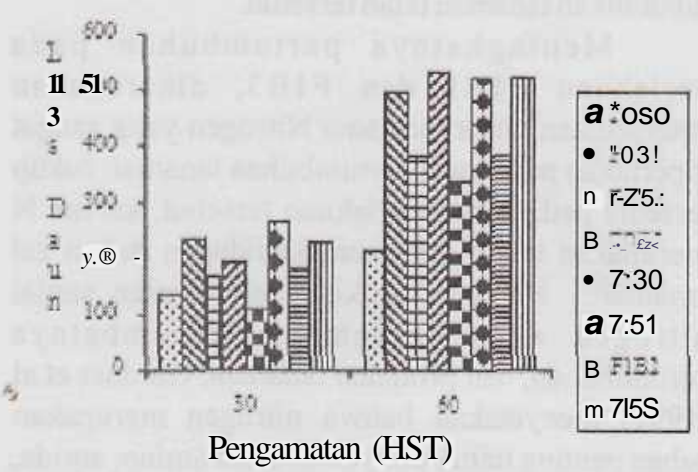

Gambar3. Pengaruh limbah makanan ternak dan biofund terhadap Luas daun pada umur 30 dan 60 HST.

\section{Produksi Tanaman}

Hasil anal'isis ragam periakuan pemberian limbah makanan ternak dengan penambahan biofund menunjukan pengaruh nyata terhadap produksi tanaman, lebih jelasnya lagi dapat dilihat padaGambar4. 


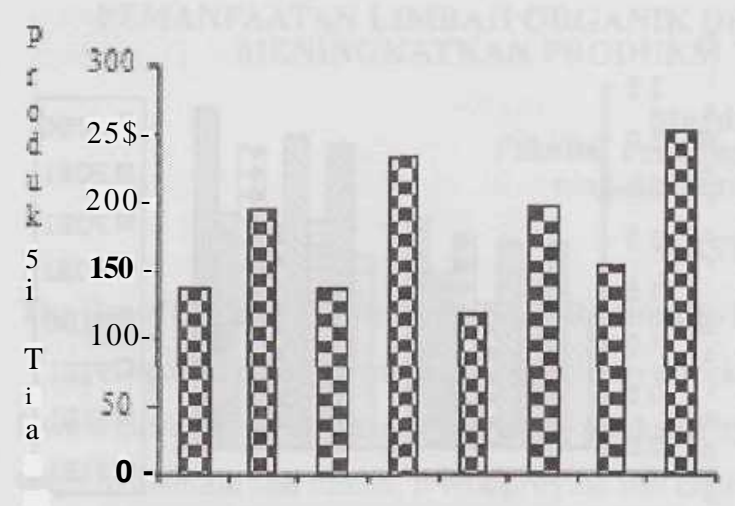

a

\section{FOBCFOBIFOBJOB5FXBGP1B1FIE2F1B5}

\section{Peslakuan}

Gambar4. Pengaruh limbah makanan ternak dan biofund terhadap Prodiiksi Tanaman.

Pertumbuhan awal tanamanjagung terlihat bahwa perlakuan FIB I dan FIB3 sudah menunjukan pertumbuhan yang berbeda dengan F1B0 dan F1B2 walaupun tingkat perbedaannya masih tetapi sudah teriihat adanya perbedaan pertumbuhan. Ini diindikasikan bahwa penggunaan limbah makanan ternak yang dicacah halus telah menunjukkan perbedaan pertumbuhan. Hal ini terjadi diduga karena pada masa inkubasi selania 20 hari bahan-bahan tersebut telah terdekomposisi dengan baik sehingga ketersediaan unsur yang dibutuhkan tanaman telah tersedia.

Meningkatnya pertumbuhan pada perlakuan FIB1 dan FIB3, dikarenakan ketersediaan unsur terutama Nitrogen yang sangat diperlukan pada awal pertumbuhan tanaman cukup tersedia pada kedua perlakuan tersebut, karena $\mathrm{N}$ merupakan unsur penyusun kehidupan dalam sel tanaman. Namun demikian keterbatasan suplai nitrogen akan berdampak terhambatnya pertumbuhan, dan produksi tanaman. Gardner et al (1991) menyatakan bahwa nitrogen merupakan bahan penting untuk penyusun asam amino, amida, nukleotida dan esensial untuk pembelahan dan pembesaran sel, oleh karena itu penting untuk pertumbuhan tanaman.

Dengan adanya masukan bahan organik dan biofund, maka terjadi peningkatan $\mathrm{N}$ mineral. Hal ini berarti bahwa sebagian $\mathrm{N}$ mineral dalam tanah telah diambil oleh tanaman sesuai kebutuhannya. Terpenuhinya kebutuhan $\mathrm{N}$ tanaman, diikuti dengan peningkatan pertumbuhan yang ditunjukan oleh adanya peningkatan parameter pertumbuhan antara lain tinggi tanaman, diameter batangJumlah daun dan luas yang meningkat hampir dua kali lipat dibandingkan dengan kontrol pada setiap periode pengamatan.
Meningkatnya pertumbuhan tanaman, sangat menunjang terhadap peningkatan produksi tanaman yaitu sebesar 252,63 dan 197,70 pada perlakuan FIB3 dan F1B1. Hal ini terjadi karena ketersediaan hara dari kedua perlakuan tersebut cukup tersedia karena sebagai akibat dari telah terdekomposisi secara sempurna. Dengan demikian dapat dikatakan bahwa kedua perlakuan tersebut merupakan perlakuan terbaik jika dibandingkan dengan perlakuan lainnya

\section{SJMPULAN}

Berdasarkan hasil penelitian yang diperoleh dan pembahasan, maka dapat ditarik kesimpulan sebagai berikut:

1. Penggunaan limbah makanan ternak dan penambahan biofund dapat meningkatkan variabel pertumbuhan yaitu tinggi tanaman, luas daun dan diameter batang tanaman.

2. Produksi yang dicapai tanaman pada semua perlakuan terlihat bahwa penggunaan sisa pakan ternak yang dicacah halus pada semua perlakuan baik dengan menggunakan biofund maupun tidak menggunakan biofund, kedua bahan tersebut menunjukkan produksi tertinggi. Produksi tertinggi dicapai pada perlakuan F1B3 yaitu sebesar 252,63 gram/tanaman, sedangkan terendah terdapat pada periakuan F1B0 yaitu sebesar 117,11 gram/tanaman.

\section{UCAPAN TERIMA KASIH}

Terima kasih kami ucapkan kepada DP2M Dirjen Dikti Depdiknas yang telah membiayai penelitian ini.

\section{DAFTARPUSTAKA}

Alegre,'j. C. and Cassel, D.K. (1996). Dynamic of soil physical properties under alternative system to Slash and Burn. In Agriculture Ecosystem and Enveronment, 58:39-48. Elsevier Science.

Anonymous (1996). Petunjuk teknis, Direktorat Penghijauan dan Perhutanan Sosial pada Rapat Kordinasi Teknis Dinas Kehutanan dan Konservasi Tanah Dati IT, Jakarta 26-28 Maret 1996.

Anonymous (2000). Peningkatan Produksi Murbei Untuk Pemeliharaan Ulat Sutera. Laporan Penelitian. PPLH Unibraw Perhutani Unit II Jawa Timur.

Anonymous, (2003). Petunjuk pemakaian Bio fund. PT. Agriguna Mandiri, Malang 
Botanri, S. dan Rossyda P. (2001). Pemanfaatan limbah organik untuk perbaikan status kesuburan tanah, produksi dan kualitas daun murbei. Jurnal Penelitian Buana Sains, Universitas Tribhuwana Tunggadewi, Malang

Handayanto, E.? Cadisch, G. and Giller, K.E. (1994). N. Release from legume hedgrouw tree prunings in relation to their quality and incubation method. Journal Plant and Soil 160,238-247.

(1995). Decomposition and mineralization of selected legume hedgrouw tree pruning. In Soil Management in Sustainable Agriculture. (Eds. H.F. Cook and H. Lee). Pp 113-120. Wye Collage University of London Press, UK.

Handayanto, E. (1996). Sinkronisasi nitrogen dalam sistem budidaya pagar : 1 . Kecepatan pelepasan nitrogen dari bahan pangkasan pohon leguminosa. Jurnal Penelitian Universitas Brawijaya $^{\wedge}$ 1-18.

(1997). Pengaruh pupuk organik cair dan kompos terhadap produksi dan kualitas daun murbei serta pertumbuhan ulat sutera dan produksi kokon. Laporan hasil penelitian, Fakultas Pertanian Universitas Brawijaya Malang.

(1999). Komponen biologi tanah sebagai bioindikator kesehatan dan produktivitas tanah. Pidato pengukuhan guru besar dalam bidang Biologi tanah, Universitas brawijaya Malang.

Haynes, R. J. 91986). The Decomposition Process Mineralization, Immobilization, Humus Formation and Degradation. In Mineral Nitrogen in the Plant Soil System: 52-109.

Katsumata, T. (1967). Technical repoet on development of sericulture in Indonesia (0,47-55.

Ladd, J. N., Oades. J.M., and Amato, A. (1985). Decomposition of plant material in Australian soil : 1. Effect of quality added on decomposition rates of residual biomass. Australian Journal of Soil Research!^, 603-611.
Mellilo, J.M., J.D. Aber and J.F. Muratore (1982). Nitrogen and lignin control of hardwood leaf litter decomposition dynamic. Journal Ecology 63,621 -626.

Moriyani, H. (2004, Serapan unsur P dan K serta pertumbuhan tanaman jagung sayur \{Baby corn) akibat penambahan activator bahan organic. Fakultas Pertanian UPN, Surabaya

Omura, S. (1967). Introduction to silkworm rearing, The japan silk Assosiation, Inc. Tokyo,pp.41-42.

Indriani, P.E. 2004. Studi Tingkat Ketersediaan Unsur (P, KTK dan C-organik) Pada Sampah Akibat Penambahan Aktivator. Faperta UPN Veteran Surabaya.

Samsijah dan Kusumaputra, S. (1975). Pengaruh penggunaan pupuk majemuk CP (1410-14-4) dalam pemeliharaan ulat sutera. Lembaga Penelitian Hutan. Laporan no. 217. Bogor.

Setiyono S,. (1996). Ffec of crops residues on soil aluminium and phosporous availability an higt activity clay (H AC) acid mineral soil. Eds. M. Van Noordwijk). Jurnal Aghvita $\% \backslash 53-\backslash 51$.

Suhardjo, H., Soepartini, M. dan Kurnia, U. (1993). Bahan organik tanah. Penelitian tanah, Air dan Lahan. Pusat Penelitian tanah dan Agroklimat, Bogor. 10-18.

Sulistiyawati, E. (2004). Dinamika pelepasan $\mathrm{NH}_{4}^{+}$ dan $\mathrm{NO}_{-}^{-}$dan koloni mikroba pada sampah akibat penambahan activator, Fakultas Pertanian UPN, Surabaya

Swift, M.J. and Sanchez, P.A. 91984). Biological management of tropical soil fertility for sustained productivity. Journal Natural and Resource 20,2-10.

Wiyono, A.R., Handayanto, E. dan Siswanto, B. (1990). Pengaruh pemberian pupuk N dan $\mathrm{K}$ terhadap kadar $\mathrm{N}$ dan $\mathrm{K}$ serta kualitas daun murbei di kebun PSA Pare. Laporan Hasil Penelitian, Universitas Brawijaya Malang. 